\title{
Total Intravenous Anesthesia for Myocardial Protection and Preconditioning
}

\author{
Minati Choudhury ${ }^{1}$ \\ ${ }^{1}$ Cardiothoracic Sciences Centre, All India Institute of Medical \\ Sciences, New Delhi, India
}

J Card Crit Care:2021;5:49-53

\begin{abstract}
Address for correspondence Minati Choudhury, MD, PGDip, Department of Cardiac Anesthesiology, Cardiothoracic Sciences Centre, All India Institute of Medical Sciences, Ansari Nagar, New Delhi 110029, India (e-mail: minati.2002@gmail.com).
\end{abstract}

\begin{abstract}
Keywords

- total intravenous anesthesia

- myocardial protection

- preconditioning

Perioperative myocardial injury is common after any major surgical procedure even with best possible anesthesia and surgical management. Organ preservation during surgical procedure prevents morbidity and mortality. The effect of ischemic preconditioning on myocardial as well as other organ protection is well known. A variety of other agents also shown to have preconditioning thus protective effect on myocardium during anesthesia and surgery. The beneficial effect of volatile anesthetic preconditioning is well studied. However, the effect of intravenous anesthetic agents on this context is still way to go. This review is an attempt to look into the latest available research regarding the preconditioning and myocardial protective effect of intravenous anesthetic agents.
\end{abstract}

\section{Introduction}

Perioperative myocardial injury is common after cardiac surgery even with best surgical procedure/anesthesia management. However, this injury is common after noncardiac surgery as well. The VISION study group in noncardiac surgery patients also noted that $8 \%$ of patients aging more that 45 years suffered from myocardial damage. The incidence of myocardial damage is again more in cases with comorbidities such as diabetes, ischemic heart disease, and/hypertension.

Perioperative organ protection is an important aspect of anesthesia and surgical management, and this is to prevent postoperative morbidity, mortality, and cost of hospital stay. Several methods have been described in literature to reduce organ damage in the perioperative period among which preconditioning is the most important one and considered to be the best.

Myocardial Injury and Preconditioning, General View, and Historical Aspect

Some degree of myocardial injury is inevitable in all kinds of surgery and that is more in cardiac surgical procedures.

published online March 27, 2021
DOI https://doi.org/ 10.1055/s-0041-1723932 ISSN 2457-0206.
Surgical trauma, mechanical stress, hemodilution, perfusion temperature, endotoxin release, ischemia-reperfusion injury, blood reaction with foreign material are the major stimulants those can give rise to ischemia, which leads to hypoxia and subsequently dysfunction of mitochondrial electron transport chain dysfunction. There occurs a decrease in adenosine triphosphate (ATP) production, induction of anaerobic metabolism, dysfunction of sodium-potassium pumps, detachment of ribosomes, and a decrease level of antioxidants in the cells. Retention of lactic acid may lead to lactic acidosis. Failure of $\mathrm{Na}^{+}-\mathrm{K}^{+}$ATPase pump and $\mathrm{Ca}^{2+}$ ATPase pump leads to accumulation of sodium, hydrogen, and calcium ions in the cell, leading to hyperosmolarity and cellular swelling. Sodium retention decreases cellular $\mathrm{pH}$, leading to the impairment of enzymatic activity and clumping of cellular chromatin. Detachment of ribosome also leads to decrease in protein synthesis. There also occurs limitation of nitric oxide bioavailability followed by apoptosis of cardiac myocytes.

After the reperfusion stage, the restoration of blood flow to ischemic tissue resumes oxygenation. In parallel, there is generation of reactive oxygen species (ROS) due to decrease (c) 2021. Official Publication of The Simulation Society (TSS), accredited by International Society of Cardiovascular Ultrasound (ISCU).

This is an open access article published by Thieme under the terms of the Creative Commons Attribution-NonDerivative-NonCommercial-License, permitting copying and reproduction so long as the original work is given appropriate credit. Contents may not be used for commercial purposes, or adapted, remixed, transformed or built upon. (https://creativecommons.org/licenses/by-nc-nd/4.0/)

Thieme Medical and Scientific Publishers Pvt. Ltd. A-12, 2nd Floor, Sector 2, Noida-201301 UP, India 
concentration of antioxidants in the ischemic cells. This leads to endothelial dysfunction, damage to DNA and local inflammatory response. The mitochondrial damage and electrolyte imbalance in this stage promotes the oxidative stress from nicotinamide adenine dinucleotide phosphate-oxidase (NADPH) oxidative system, nitric oxide synthase system and xanthine oxidase system as well as mitochondrial electron transport system. There is activation of inflammatory cascade leading to a cytokine storm, and retention of ROS leading to cellular damage and cell death via mitoptosis, autophagy, necrosis, necroptosis as well as apoptosis. This reperfusion phase is dynamic and sometimes persists for several days. ${ }^{1}$ Understanding the detailed mechanism of ischemia-reperfusion injury may provide a strong foundation not only for novel therapeutic opportunities, but also for injury prevention.

In literary meaning, preconditioning $(\mathrm{PC})$ is nothing but "adaptation," in which a living entity is exposed to a form of stress or stimulus or environment to prepare that subject to be more resilient against the stimulus if it is encountered/ applied thereafter. The concept of myocardial preconditioning was narrated first by Murray et al way back in 1986 . He with his team used ischemia as a stimulus and described ischemic preconditioning (IPC) in dog hearts. In these experiments, one group of dogs was preconditioned with four cycles ( 5 minutes each) of circumflex artery occlusions, each separated by 5 minutes of reperfusion and followed by continuous 40 minutes occlusion. The control group underwent a single 40 minutes occlusion only. The authors noted a reduction in infarct size (IS) to $25 \%$ when compared with the control group $(p=0.001){ }^{2}$

Several cardioprotective strategies like cardioplegia, hypothermia, warm heart surgery, ischemic preconditioning, ischemic postconditioning, remote ischemic preconditioning, use of glucose-insulin in cardioplegia, and nitric oxide-L arginine supplemented cardioplegia are in use.,4 ${ }^{3,4}$ cardio protective effects of volatile anesthetics are widely studied by several authors in the past few decades. These investigators have shown that exposure to volatile anesthetics leads to a variety of changes in the protein structure of the myocardium. These changes in protein structure and their modified distribution after exposure to volatile anesthetic agents can mediate myocardial protection (MP) by preconditioning effect. There exist three windows where MP strategies can be implemented, for example, before ischemia (preconditioning), during ischemia, and after ischemia (postconditioning). ${ }^{5-8}$ There is a paucity of literature when myocardial preservation and preconditioning concerned with intravenous anesthetists. Intravenous anesthetics may be the future of cardioprotection; however, it is superiority to volatile anesthetists and other agents as well as ischemic preconditioning are yet to be proved. Fraßdorf et al in one of the reviews narrated the possible protective role of intravenous anesthetics against ischemia and reperfusion injuries. ${ }^{9}$ The main advantages of APC by anesthetic agents are that, unlike IPC, APC is not selective to myocardium only. The beneficial effects of these agents are for the entire organs of the body. APC is again easy way, less cumbersome because these agents are mandatory during any of the surgical procedures. This review is an attempt to reveal this concept with basic cellular mechanisms and recent trends.

\section{Myocardial Protection and Preconditioning by Intravenous Anesthetic Agents, Mechanisms to Clinical Outcome}

One of the frequent challenges of current day anesthesia practice is the prevention and treatment of myocardial ischemia and reperfusion injury. The primary goal in the therapy of myocardial ischemia-related injury is to restore perfusion to the ischemic tissues. The more lethal reperfusion injury can be reduced by modifications of conditions of reperfusion. Among all modifying agents, intravenous anesthetic agents are some. The mechanism involving anesthetic preconditioning (APC) is similar to reperfusion injury salvage kinase (RISK) that of IPC and ischemic postconditioning (IPoC). APC-MP is primarily mediated by RISK and survivor activating factor enhancement (SAFE) pathways. The activation of RISK pathway is via G-protein coupled cell surface receptor and that of SAFE pathway is via TNF- $\alpha$ receptor; both of which inhibit ischemia reperfusion injury (IRI) induced mitochondrial permeability transition pathway (MPTP) opening and activate the opening of KATP channels which subsequently protects cardiomyocyte from IRI induced cell death.

\section{Opioids and Its Derivatives}

Previous studies have demonstrated that opioid like agents bestow the ability of cardiac tissue to tolerate periods of ischemia and hypoxia. ${ }^{10}$ Morphine is one of the first agents to be tested for its cardioprotective effect by Schultz et al. In this experimental model, the authors elicited morphine induced PC by 5 minutes of drug infusion ( $100 \mu \mathrm{gm} / \mathrm{kg} \mathrm{IV})$ interspersed with 5 minutes drug free periods before the prolonged 30 minutes occlusion. The control group underwent three cycles of IPC. A similar reduction of IS to the area at risk happened in all the subjects. Their results indicate that the effect of morphine induced PC is most likely mediated via an opioid receptor-linked mechanism, which is similar to IPC. ${ }^{11}$ Murphy et al in one of the prospective randomized studies on coronary artery bypass grafting (CABG) patients, administered either morphine $40 \mathrm{mg}$ or fentanyl 1,000 $\mu \mathrm{gm}$ before $\mathrm{CPB}$. The morphine receivers showed an improvement of myocardial performance index 15 minutes post-CPB and end of surgery when compared with baseline and fentanyl group. However, this study does not comply with the strict definition of preconditioning. ${ }^{12}$ The protection against IRI to myocardium is offered by opioids mediated via stimulation of generation of ROS, which triggers and enhances the production of endogenous antioxidant enzymes and activates mitochondrial KATP channels, limiting myocardial infarction..$^{13}$ Previous studies concluded the role of opioids in myocardial hibernation. Both endogenous and exogenous opioid agonists (morphine and remifentanil) reduce myocardial oxidative stress and $\mathrm{Ca}^{2+}$ overload attenuate myocardial IRI in patients undergoing cardiac surgery. ${ }^{12,13}$ Qiao et al in one of their initial experimental models show that remifentanil confers MP primarily via activation of JAK2/STAT3 signaling that can function independent of PI3K/AKt activation ${ }^{14}$ 


\section{Propofol}

The propofol induced myocardial preconditioning is mediated via its ROS scavenging properties, which enhances endogenous myocardial antioxidant capacity and thereby attenuates myocardial IRI. Few of the authors also suggested that propofol-induced MP may partly result from a direct effect on myocardial $\mathrm{Ca}^{2+}$ influx or from inhibition of mPTP. Opening of MPTP uncouples mitochondria and is involved in determining pathways that lead to apoptosis and necrosis. ${ }^{15}$ Inspite of the fact that propofol protects against IRP when given before onset of ischemia, its administration on reperfusion alone may be ineffective. Administration of propofol $(120 \mu \mathrm{gm} / \mathrm{kg} / \mathrm{min}$ for 10 minutes) before the commencement of CPB until 15 minutes after aortic cross clamp release, than $60 \mu \mathrm{gm} / \mathrm{kg} / \mathrm{min}$ till the end of surgery, significantly attenuated myocardial injury as evidenced by a reduction in cardiac troponin $\mathrm{I}(\mathrm{CTnI})$ release as noted by Xia et al. ${ }^{16}$ Bulow et al compared dexmedetomidine $0.3 \mu \mathrm{gm} / \mathrm{kg} / \mathrm{h}$ in patients undergoing on-pump CABG to that with propofol $4 \mu \mathrm{gmL} / \mathrm{min}$. A reduced oxidative stress markers and inflammatory markers was found with both the drugs. ${ }^{17}$ The benefits of propofol as APC was demonstrated by several authors; however, few of the trials showed that no difference among patients receiving propofol or sevoflurane and propofol or desflurane in terms of CK-MB, CTnI level, and postoperative recovery parameters. ${ }^{18}$

\section{Ketamine}

While one of the researchers reported that racemic mixture of ketamine blocks IPC of the myocardium, Hanouz et al found that both racemic and S+ isomer of ketamine induced preconditioning effect in isolated human myocardium. Their inference was ketamine-induced preconditioning involved activation of potassium adenosine triphosphate $\mathrm{K}$ (ATP) channels and stimulation of $\alpha$ and $\beta$ adrenergic receptors. ${ }^{19}$

In another experimental study, the authors found that higher dose of ketamine-xyaline (KX) (K: $200 \mathrm{mg} / \mathrm{kg}$; X: $60 \mathrm{mg}$ / $\mathrm{kg}$ or $\mathrm{K}: 85 \mathrm{mg} / \mathrm{kg}$; $\mathrm{X}: 15 \mathrm{mg} / \mathrm{kg}$ ) used to anesthetize guinea pigs led to reduction in myocardial IS and improved hemodynamics after experimental ischemia-reperfusion injury. ${ }^{20}$

Table 1 The major randomized clinical trials of total intravenous anesthesia in myocardial protection and preconditioning

\begin{tabular}{|c|c|c|c|c|}
\hline Reference no. & Induction agents & Test drug for APC & Control drug & Effect \\
\hline 17 & $\begin{array}{l}\text { Sufentanil } 0.5-1 \mu \mathrm{gm} / \mathrm{kg} \\
\text { followed by } 0.5-1 \mu \mathrm{gm} / \mathrm{kg} / \mathrm{h}\end{array}$ & $\begin{array}{l}\text { Dexmedetomidine } \\
0.3 \mu \mathrm{gm} / \mathrm{kg} / \mathrm{h}\end{array}$ & Propofol & $\begin{array}{l}\text { Oxidative stress and } \\
\text { inflammatory markers }\end{array}$ \\
\hline 23 & Midazolam-propofol-fentanyl & Propofol & Sevoflurane & Postoperative lymphedema \\
\hline 24 & Institutional protocol & $\begin{array}{l}\text { Dexmedetomidine- } \\
\text { Lidocaine }\end{array}$ & Isoflurane & CTnl and CK-MB \\
\hline 25 & Fentanyl-Etomidate & Desflurane & Propofol & $\begin{array}{l}\text { No difference in cardiac function, } \\
\text { CTnl and CK-MB }\end{array}$ \\
\hline 26 & Fentanyl-Midazolam & Sevoflurane & Propofol & No difference in CTnl \\
\hline 27 & Etomidate-Midazolam-Fentanyl & Sevoflurane & Propofol & $\begin{array}{l}\text { No difference in CTnl, CK-MB, } \\
\text { NT-ProBNP, hemodynamics and } \\
\text { duration of stay in hospital or } \\
\text { intensive care unit }\end{array}$ \\
\hline 28 & Etomidate-Sufentanil & $\begin{array}{l}\text { Propofol } \\
\text {-Isoflurane }\end{array}$ & Midazolam & $\begin{array}{l}\text { CTnl is more in Propofol- } \\
\text { Isoflurane group }\end{array}$ \\
\hline 29 & $\begin{array}{l}\text { Midazolam- } \\
\text { Dexmedetomidine-Ketamine }\end{array}$ & $\begin{array}{l}\text { Midazolam } \\
\text {-Dexmedetomidine } \\
\text {-Ketamine }\end{array}$ & Sevoflurane & CTnl and CK-MB \\
\hline 30 & Thiopentone-Fentanyl & Isoflurane & Propofol & $\begin{array}{l}\text { Similar in CTnl and CK-MB in both } \\
\text { the groups }\end{array}$ \\
\hline 31 & Fentanyl & $\begin{array}{l}\text { Remifentanil till } \\
\text { sternotomy-propofol }\end{array}$ & $\begin{array}{l}\text { Normal saline till } \\
\text { sternotomy-propo- } \\
\text { fol }\end{array}$ & $\begin{array}{l}\text { In CTnl, CK-MB and h-fatty acid } \\
\text { binding protein in remifentanyl } \\
\text { recievers }\end{array}$ \\
\hline 32 & $\begin{array}{l}\text { Midazolam-Sufe } \\
\text { ntanyl }\end{array}$ & $\begin{array}{l}\text { Ketamine } \\
\text {-Sevoflurane } \\
\text {-Fentanyl }\end{array}$ & $\begin{array}{l}\text { Normal saline } \\
\text { Sevoflurane- } \\
\text { Fentanyl }\end{array}$ & $\begin{array}{l}\text { No effect on pro-inflammatory } \\
\text { cytokine release }\end{array}$ \\
\hline 33 & Opioid-Isoflurane & Morphine & Fentanyl & Inflammatory response \\
\hline 34 & Fentanyl-Isoflurane & $\begin{array}{l}\text { Fentanyl-Isoflurane } \\
\text { Propofol before aortic } \\
\text { cross clamp release till } \\
4 \text { hours after reperfusion }\end{array}$ & $\begin{array}{l}\text { Fentanyl-Isoflurane } \\
\text { Normal before } \\
\text { aortic cross clamp } \\
\text { release till } 4 \text { hours } \\
\text { after reperfusion }\end{array}$ & $\begin{array}{l}\text { Free radical mediated lipid } \\
\text { peroxidation and decreased } \\
\text { systemic inflammation }\end{array}$ \\
\hline 16 & Midazolam-Fentanyl & Propofol & Isoflurane & CTnl and oxidative stress markers \\
\hline
\end{tabular}

Abbreviations: APC, anesthetic preconditioning; I, decrease; CTnl, cardiac troponin I; CK-MB, creatinine kinase myocardial band; NT-Pro BNP, N-terminal pro- $\beta$ natriuretic peptide. 


\section{Barbiturates}

The ROS scavenging ability of barbiturates has been found in experimental models is lesser than that of propofol. Thiopental is the most potent agent among all the barbiturates for APC when renal, bowel, and neuronal ischemia is concerned, but there is migre literature concerning its effect on myocardial ischemia and reperfusion injury. ${ }^{21}$

\section{Etomidate}

This drug does not have any effect on adhesion of neutrophils to coronary endothelium in postischemic myocardium. There is no clinical report regarding its effect on PC of myocardium. ${ }^{22}$

\section{Benzodiazepines}

The impact of midazolam on ROS formation is much less than that of propofol and there are conflicting reports regarding the effect of benzodiazepines on MP. The following - Table 1 enumerates some of the trials narrating the preconditioning effect of intravenous anesthetic agents.

\section{Future Directives}

We have achieved a bit in the field of MP and preconditioning by intravenous anesthetic agents. However, we have still miles to go. Volatile anesthetics are the first choice for APC both in noncardiac and cardiac surgical patients. However, there is growing evidence that few of the intravenous agents, especially opioids, propofol, and dexmedetomidine are good anesthetics for APC. Still, there is a lot of doubts that large-scale nonrandomized trials will be performed in the near future to tackle this question. The more challenging situation arises when age, diabetes, and myocardial remodeling diminishes APC. Again, there is significant interference in MP effect between sevoflurane and propofol, which should not be used concomitantly if possible. All the researchers are still waiting for a promising outcome with the best method and magic dose of IV anesthetic agents to provide APC in future.

\section{Funding}

None.

\section{Conflict of Interest}

None declared.

\section{References}

1 Carden DL, Granger DN. Pathophysiology of ischaemia-reperfusion injury. J Pathol 2000;190(3):255-266

2 Murry CE, Jennings RB, Reimer KA. Preconditioning with ischemia: a delay of lethal cell injury in ischemic myocardium. Circulation 1986;74(5):1124-1136

3 Jović M, Krivokapić B, Lausević-Vuk L, Nezić D, Stevanović P. [Strategy and perspective of myocardial protection during ischaemia and reperfusion, and the role of volatile anaesthetics]. Srp Arh Celok Lek 2007;135(9-10):583-588

4 Granfeldt A, Lefer DJ, Vinten-Johansen J. Protective ischaemia in patients: preconditioning and postconditioning. Cardiovasc Res 2009;83(2):234-246

5 de Ruijter W, Musters RJP, Boer C, Stienen GJM, Simonides WS, de Lange JJ. The cardioprotective effect of sevoflurane depends on protein kinase $\mathrm{C}$ activation, opening of mitochondrial $\mathrm{K}(+)$
(ATP) channels, and the production of reactive oxygen species. Anesth Analg 2003;97(5):1370-1376

6 Weber NC, Schlack W. Inhalational anaesthetics and cardioprotection. Handb Exp Pharmacol 2008;182(182):187-207

7 Siracusano L, Girasole V, Alvaro S, Chiavarino ND. Myocardial preconditioning and cardioprotection by volatile anaesthetics. J Cardiovasc Med (Hagerstown) 2006;7(2):86-95

8 Landoni G, Fochi O, Bignami E, et al. Cardiac protection by volatile anesthetics in non-cardiac surgery? A meta-analysis of randomized controlled studies on clinically relevant endpoints. HSR Proc Intensive Care Cardiovasc Anesth 2009;1(4):34-43

9 Frässdorf J, De Hert S, Schlack W. Anaesthesia and myocardial ischaemia/reperfusion injury. Br J Anaesth 2009;103(1):89-98

10 Mayfield KP, D’Alecy LG. Delta-1 opioid receptor dependence of acute hypoxic adaptation. J Pharmacol Exp Ther 1994;268(1):74-77

11 Schultz JE, Rose E, Yao Z, Gross GJ. Evidence for involvement of opioid receptors in ischemic preconditioning in rat hearts. Am J Physiol 1995;268(5 Pt 2) :H2157-H2161

12 Murphy GS, Szokol JW, Marymont JH, Avram MJ, Vender JS. Opioids and cardioprotection: the impact of morphine and fentanyl on recovery of ventricular function after cardiopulmonary bypass. J Cardiothorac Vasc Anesth 2006;20(4):493-502

13 Tanaka K, Weihrauch D, Kehl F, et al. Mechanism of preconditioning by isoflurane in rabbits: a direct role for reactive oxygen species. Anesthesiology 2002;97(6):1485-1490

14 Qiao S, MaoX, Wang Y, et al. Remifentanil preconditioning reduces postischemic myocardial infarction and improves left ventricular performance via activation of the Janus activated kinase-2/ signal transducers and activators of transcription-3 signal pathway and subsequent inhibition of glycogen synthase kinase3beta in rats. Crit Care Med 2016;44(3):e131-e145

15 Kowaltowski AJ, Castilho RF, Vercesi AE. Mitochondrial permeability transition and oxidative stress. FEBS Lett 2001;495(1-2):12-15

16 Xia Z, Huang Z, Ansley DM. Large-dose propofol during cardiopulmonary bypass decreases biochemical markers of myocardial injury in coronary surgery patients: a comparison with isoflurane. Anesth Analg 2006;103(3):527-532

17 Bulow NM, Colpo E, Pereira RP, et al. Dexmedetomidine decreases the inflammatory response to myocardial surgery under mini-cardiopulmonary bypass. Braz J Med Biol Res 2016;49(4):e4646

18 Kunst G, Klein AA. Peri-operative anaesthetic myocardial preconditioning and protection - cellular mechanisms and clinical relevance in cardiac anaesthesia. Anaesthesia 2015;70(4):467-482

19 Hanouz JL, Zhu L, Persehaye E, et al. Ketamine preconditions isolated human right atrial myocardium: roles of adenosine triphosphate-sensitive potassium channels and adrenoceptors. Anesthesiology 2005;102(6):1190-1196

20 Sloan RC, Rosenbaum M, O'Rourke D, et al. High doses of ketamine-xylazine anesthesia reduce cardiac ischemia-reperfusion injury in guinea pigs. J Am Assoc Lab Anim Sci 2011;50(3):349-354

21 Tamaki F, Oguchi T, Kashimoto S, Nonaka A, Kumazawa T. Effects of propofol on ischemia and reperfusion in the isolated rat heart compared with thiamylal. Jpn Heart J 2001;42(2):193-206

22 KrumholzW,DemelC,Jung S, Meuthen G, KnechtJ,Hempelmann $\mathrm{G}$. The effects of thiopentone, etomidate, ketamine and midazolam on several bactericidal functions of polymorphonuclear leucocytes in vitro. Eur J Anaesthesiol 1995;12(2):141-146

23 Jia L, Dong R, Zhang F, et al. Propofol provides more effective patients undergoing off-pump coronary artery bypass graftsurgery. J Cardiothorac Vasc Anesth 2015;29:1172-1179

24 Kim HJ, Kim WH, Kim G, et al. A comparison among infusion of lidocaine and dexmedetomidine alone and in combination 
in subjects undergoing coronary artery bypass graft: a randomized trial. Contemp Clin Trials 2014;39(2):303-309

25 Mroziński P, Lango R, Biedrzycka A, Kowalik MM, Pawlaczyk R, Rogowski J. Comparison of haemodynamics and myocardial injury markers under desflurane vs. propofol anaesthesia for off-pump coronary surgery. A prospective randomised trial. Anaesthesiol Intensive Ther 2014;46(1):4-13

26 Suryaprakash S, Chakravarthy M, Muniraju G, et al. Myocardial protection during off pump coronary artery bypass surgery: a comparison of inhalational anesthesia with sevoflurane or desflurane and total intravenous anesthesia. Ann Card Anaesth 2013;16(1):4-8

27 Soro M, Gallego L, Silva V, et al. Cardioprotective effect of sevoflurane and propofol during anaesthesia and the postoperative period in coronary bypass graft surgery: a double-blind randomised study. Eur J Anaesthesiol 2012;29(12):561-569

28 Imantalab V, Seddighi Nejad A, Mir Mansouri A, et al. A comparative study of cardioprotective effect of three anesthetic agents by measuring serum level of troponin-T after coronary artery bypass grafting. Int Cardiovasc Res J 2012;6(3):70-74

29 Ríha H, Kotulák T, Březina A, et al. Comparison of the effects of ketamine-dexmedetomidine and sevoflurane-sufentanil anesthesia on cardiac biomarkers after cardiac surgery: an observational study. Physiol Res 2012;61(1):63-72
30 Tempe DK, Dutta D, Garg M, Minhas H, Tomar A, Virmani S. Myocardial protection with isoflurane during off-pump coronary artery bypass grafting: a randomized trial. J Cardiothorac Vasc Anesth 2011;25(1):59-65

31 Wong GT, Huang Z, Ji S, Irwin MG. Remifentanil reduces the release of biochemical markers of myocardial damage after coronary artery bypass surgery: a randomized trial. J Cardiothorac Vasc Anesth 2010;24(5):790-796

32 Cho JE, Shim JK, Choi YS, Kim DH, Hong SW, Kwak YL. Effect of low-dose ketamine on inflammatory response in off-pump coronary artery bypass graft surgery. $\mathrm{Br}$ J Anaesth 2009;102(1):23-28

33 Murphy GS, Szokol JW, Marymont JH, Avram MJ, Vender JS. The effects of morphine and fentanyl on the inflammatory response to cardiopulmonary bypass in patients undergoing elective coronary artery bypass graft surgery. Anesth Analg 2007;104(6):1334-1342

34 Corcoran TB, Engel A, Sakamoto H, O'Shea A, O'Callaghan-Enright S, Shorten GD. The effects of propofol on neutrophil function, lipid peroxidation and inflammatory response during elective coronary artery bypass grafting in patients with impaired ventricular function. $\mathrm{Br}$ J Anaesth 2006;97(6):825-831 